\title{
In vitro evaluation of BACtrackR's smartphone-connected personal breath alcohol analyzers
}

\author{
Aaron Olson
}

December 1, 2021

\begin{abstract}
This study assessed the in vitro accuracy, precision, specificity, and measurement uncertainty of BACtrack $@$ 's line of smartphone-connected breath alcohol analyzers. At the $0.080 \mathrm{~g} / 210 \mathrm{~L}$ ethanol vapor concentration the measurement uncertainty was determined to be $\pm 0.013,0.004$, and $0.006 \mathrm{~g} / 210 \mathrm{~L}$ for the Pro, C8, and C6 respectively at the 95\% coverage interval. The analyzers showed an apparent ethanol respon-

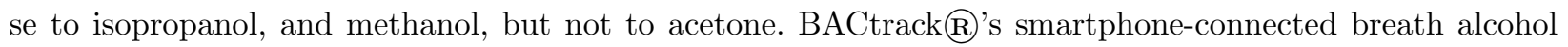
analyzers showed the ability to measure vaporous ethanol with confidence in the results.
\end{abstract}

\section{Introduction}

The ability to easily monitor one's breath alcohol concentration (BrAC) may be useful in situations where driving a vehicle above a certain limit constitutes a violation of the law. Other potential uses include remote monitoring of alcohol use (1), self-tracking $(2 ; 3)$, use in drinking establishments (4), medicine $(5 ; 6)$, family law (7), research (8) and workplace testing (9).

Scant research exists on the performance of small, inexpensive breath alcohol analyzers marketed for personal use. In 2003, Van Tassel coined the phrase, "pocket model breath tester" (PMBT) to describe such a device and found most of the devices examined to be lacking in analytical performance (10). More recent examinations of these types of devices have shown mixed results $(11 ; 12 ; 13 ; 14 ; 15)$.

This study assessed BACtrack $(\mathbb{R}$ 's line of smartphone-connected breath alcohol analyzers in vitro against known reference standards. The analyzers were evaluated for accuracy, precisi- 
on, specificity, and measurement uncertainty. Special attention was paid to the measurement uncertainty at the $0.080 \mathrm{~g} / 210 \mathrm{~L}$ ethanol vapor concentration due to its legal implications in the United States and other countries.

\section{Materials}

\section{BACtrack@ Breath Alcohol Analyzers}

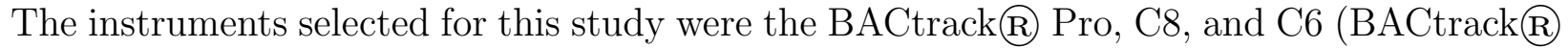
Breathalyzers, San Francisco CA, USA). One of each instrument was purchased new from an internet retailer. The cost of the instruments was: $\$ 79, \$ 99$, and $\$ 99$ for the C6, C8, and Pro respectively. The same instruments were used for the entirety of this study. The instruments cannot be calibrated locally by the end-user but must be sent back to the manufacturer every 6-12 months for recalibration.

The analyzers connect via Bluetooth@ to an app installed on the user's smartphone where measurements can be displayed and recorded. Two of the instruments, the C6 and C8, can also be used in a standalone mode where a smartphone app is not required. When used in standalone mode, results display on a small screen built into the device. The Pro model requires the use of the companion smartphone app.

The dimensions of the instruments are: $6.98 \times 4.44 \times 1.60,6.35 \times 5.58 \times 1.67$, and $5.61 \times 4.76$ x $1.67 \mathrm{~cm}$, for the Pro, C8 and C6 respectively (16; 17; 18). Figure 1 shows a picture of the BACtrack R Pro, C8, and C6 from left to right with a AAA size battery included on the far left for scale. 


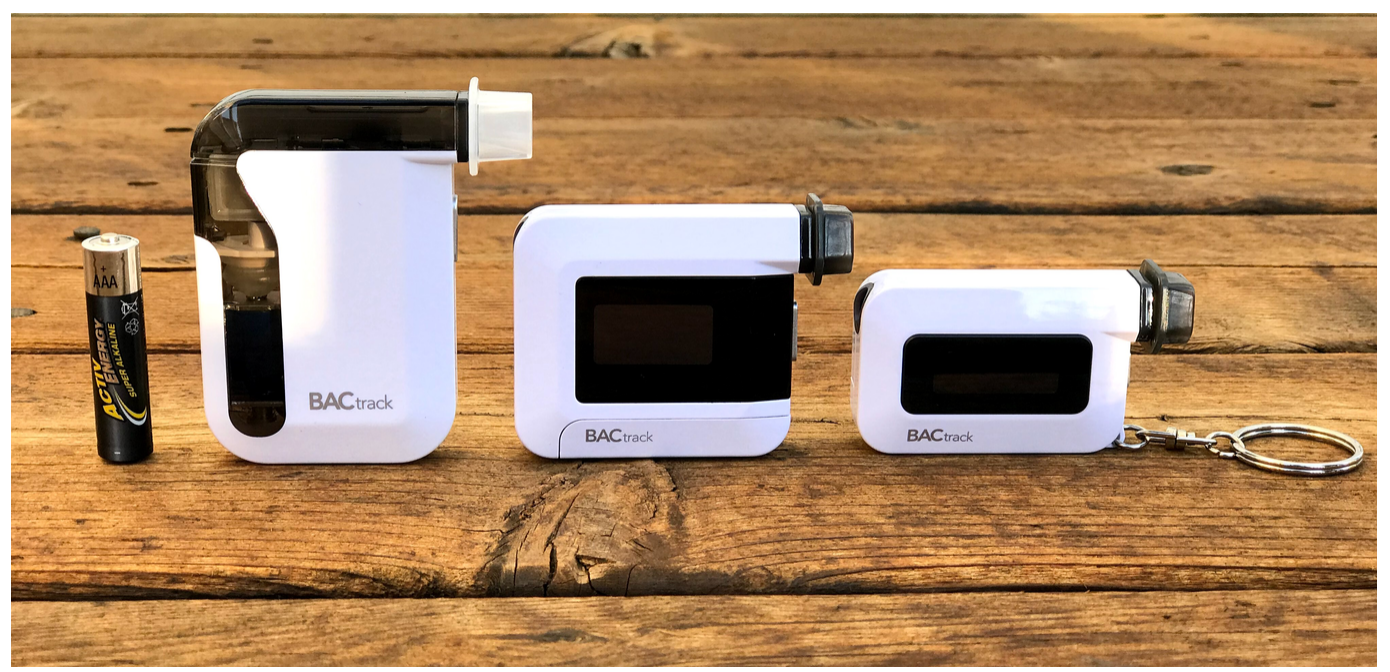

Figure 1: BACtrack@ Pro, C8, and C6

Before testing, users must abstain from drinking alcohol for a period of at least 15-minutes. This allows for residual alcohol in the mouth from recent drinking to dissipate so as not to falsely elevate the test $(19 ; 20 ; 21 ; 22 ; 23)$. The instruments do not have a mechanism to monitor for residual mouth alcohol, such as those used in more advanced infrared breath alcohol analyzers (24).

To start the testing process, the user powers-on the instrument and follows onscreen instructions to blow into the device. The user must provide a breath at a flow rate of $12-14 \mathrm{~L} / \mathrm{m}$ for approximately 5 seconds, resulting in a total volume of breath provided of approximately 1.2L (email communication, BACtrack $\mathrm{R}$. Breathalyzers). The result of the breath alcohol analysis is shown onscreen to the third decimal in $\mathrm{g} / 210 \mathrm{~L}$. Users have the ability to change the units of concentration if desired.

As the user blows into the instrument, ethanol is introduced to an electrochemical fuel cell via a miniature solenoid pump (25). Ethanol on the user's breath is oxidized with the platinum black coated fuel cell, producing electrons (26). The electrical response generated is proportional to the ethanol concentration on the user's breath (27). There is no exhalation profile of alcohol as seen in more sophisticated infrared breath alcohol analyzers (26).

After analysis, the app will display a predicted "time-to-sober" (BrAC of 0.000), based on an ethanol elimination rate of $0.015 \mathrm{~g} / 210 \mathrm{~L} / \mathrm{hr}$. The instrument and companion app are programmed to calculate "time-to-sober" using zero-order kinetics, even when results are below $0.020 \mathrm{~g} / 210 \mathrm{~L}$ and zero-order kinetics cannot be assumed (28). Instruments are pro- 
grammed for a single breath sample to be obtained for analysis and cannot be programmed for a duplicate test sequence. Results can be saved in the smartphone app but cannot be exported to a spreadsheet for further analysis.

A novel aspect of the analyzers is the ability to record and share measurements via the companion smartphone app. When paired to the app, users can keep a record of all previous data, guess one's BrAC prior to testing, change the units of the reported concentration, upload photos, number of drinks, notes, share results, view other anonymous results on a map, and call for an Uber ride.

When used for remote monitoring of alcohol, the results of the test along with a picture of the user blowing into the device, and the GPS location can be uploaded to a database where approved third parties can monitor results. Reports from remote monitoring can be produced in a portable document format (PDF), but cannot be exported to a spreadsheet for further analysis (29).

Rich media available at https://youtu.be/KbwkpqPBslo

\section{Breath Simulators}

Reference vapors were produced using two breath simulators, RepCo Model 3402C (RepCo Marketing, Co. Raleigh, NC, USA), in tandem (also known as a bubble train) to improve the performance of reference material as described by Dubowski (30) and others (31; 32; $33 ; 34)$. Breath simulators were driven by human breath. Figure 2 shows the tandem breath simulator set-up. 


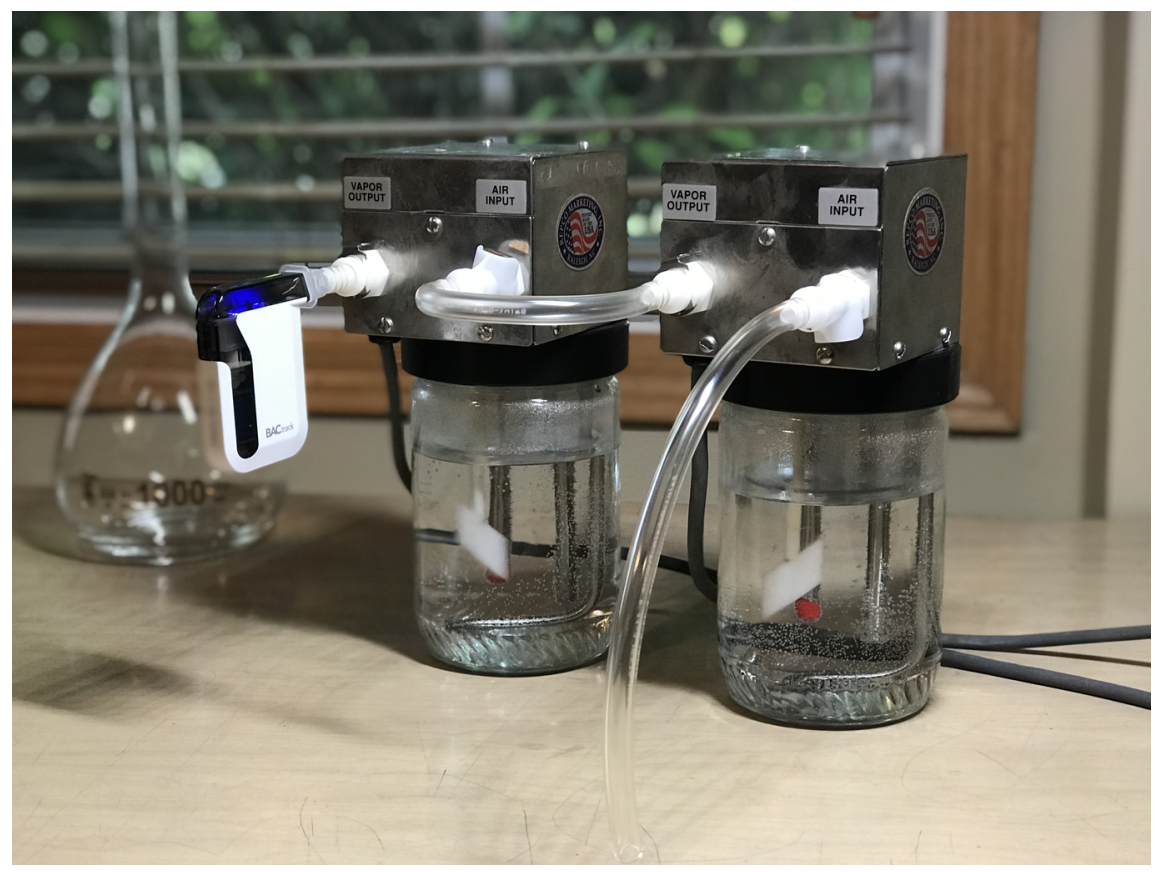

Figure 2: Breath simulator set-up

\section{Aqueous Reference Standards}

Aqueous reference standards were volumetrically prepared to produce reference vapors at specified concentrations when used in a breath simulator heated to $34^{\circ} \mathrm{C}$, in accordance with Henry's Law (35). Class A glassware, American Chemical Society/United States Pharmacopeia grade chemicals, and purified water were used. Ethanol reference standards were prepared to produce vapor concentrations of $0.020,0.040,0.080,0.160,0.250 \mathrm{~g} / 210 \mathrm{~L}$ using Harger's water/air partition coefficient of $2539: 1$ at $34^{\circ} \mathrm{C}(36)$. Reference vapors of potentially interfering substances were prepared to produce vapor concentrations of acetone, isopropanol, and methanol at $0.5,0.1,0.1 \mathrm{mg} / \mathrm{L}$ respectively (34). Water/air partition coefficients for potential interfering substances at $34^{\circ} \mathrm{C}$ were obtained from the literature (37).

\section{Methods}

Ten measurements were taken with each instrument at each ethanol reference vapor concentration, as well as ten measurements of each potentially interfering substance concentration (38). Measurements were alternated with the Pro, C8, and C6 at approximately 2-minute 
intervals. The mean, standard deviation (SD), bias, $\mathrm{R}^{2}$ and ordinary least squares regression (OLSR) were calculated. Apparent ethanol response to potential interfering substances was recorded. An evaluation of the potential sources of uncertainty was evaluated using an Ishikawa diagram (39) as seen in figure 3.

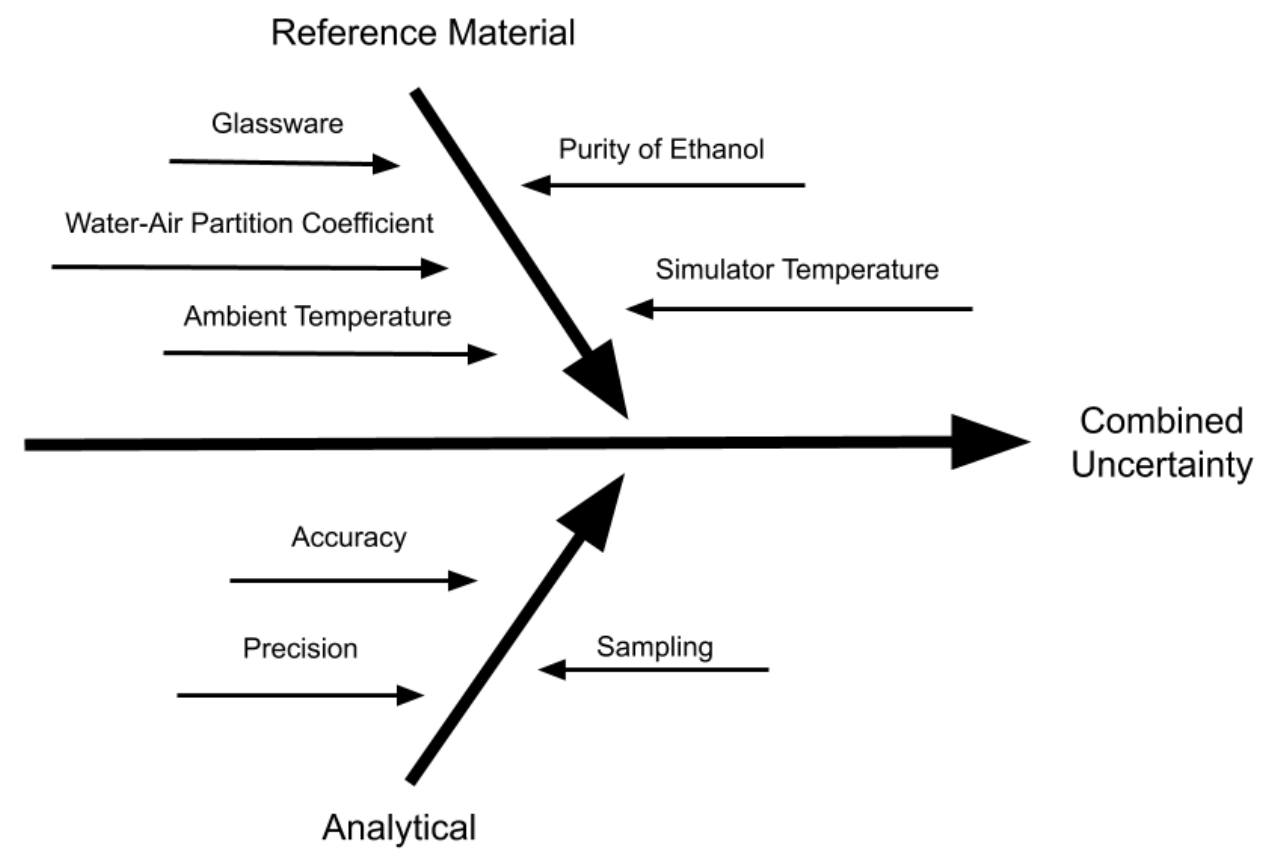

Figure 3: Ishikawa diagram showing uncertainty components

Standard uncertainties were combined using the root-sum-squares approach where, $u_{\text {combined }}=\sqrt{u_{\text {precision }}^{2}+u_{\text {bias }}^{2}+u_{\text {reference }}^{2}}(40 ; 41)$. Bias was incorporated as a component under the radical in the estimate of measurement uncertainty, expanding the coverage interval $(42 ; 43)$. The combined standard uncertainty was expanded to the $95 \%$ coverage interval where, $U_{95 \%}=2 u_{\text {combined }}$. Figure 4 shows the mean individual uncertainty component's percent contribution to the combined standard uncertainty. 


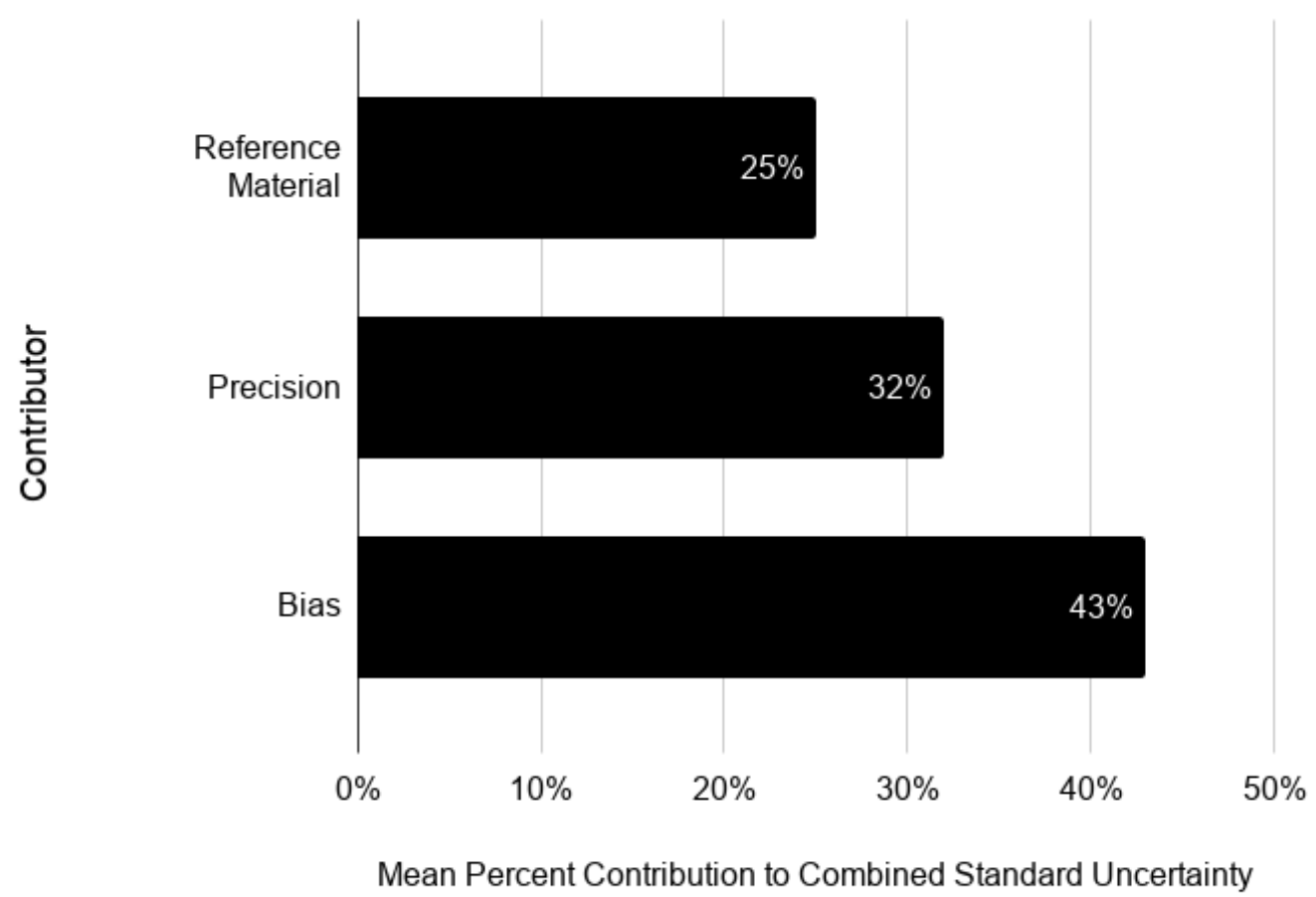

Figure 4: Percent contribution to the combined standard standard uncertainty

\section{Results}

The mean, $\mathrm{R}^{2}$, and OLSR are summarized in table 1 . The $\mathrm{SD}$ of the measurements are displayed in table 2. Bias is shown in table 3 . At the $0.080 \mathrm{~g} / 210 \mathrm{~L}$ concentration, the combined expanded measurement uncertainty was determined to be $\pm 0.013,0.004$, and $0.006 \mathrm{~g} / 210 \mathrm{~L}$ at the $95 \%$ coverage interval for the Pro, C8, and C6 respectively. Instruments did not respond to acetone but did respond to isopropanol and methanol as seen in table 4 .

$\begin{array}{llllllll}\text { Concentration }(\mathrm{g} / 210 \mathrm{~L}) & 0.020 & 0.040 & 0.080 & 0.160 & 0.250 & \mathrm{R}^{2} & \text { OLSR } \\ \text { Pro } & 0.0230 & 0.0460 & 0.0909 & 0.1780 & 0.2720 & 0.99 & \mathrm{y}=1.08 \mathrm{x}+0.003 \\ \text { C8 } & 0.0205 & 0.0390 & 0.0793 & 0.1495 & 0.2258 & 0.99 & \mathrm{y}=0.89 \mathrm{x}+0.005 \\ \text { C6 } & 0.0196 & 0.0369 & 0.0762 & 0.1403 & 0.2125 & 0.99 & \mathrm{y}=0.84 \mathrm{x}+0.005\end{array}$

Table 1: Mean, $\mathrm{R}^{2}, O L S R$ 


$\begin{array}{llllll}\text { Concentration }(\mathrm{g} / 210 \mathrm{~L}) & 0.020 & 0.040 & 0.080 & 0.160 & 0.250 \\ \text { Pro } & 0.0000 & 0.0000 & 0.0007 & 0.0005 & 0.0029 \\ \text { C8 } & 0.0007 & 0.0012 & 0.0015 & 0.0040 & 0.0034 \\ \text { C6 } & 0.0005 & 0.0012 & 0.0021 & 0.0051 & 0.0081\end{array}$

Table 2: Standard Deviation

$\begin{array}{llllll}\text { Concentration }(\mathrm{g} / 210 \mathrm{~L}) & 0.020 & 0.040 & 0.080 & 0.160 & 0.250 \\ \text { Pro } & 0.0030 & 0.0060 & 0.0109 & 0.0180 & 0.0220 \\ \text { C8 } & 0.0005 & -0.0010 & -0.0007 & -0.0105 & -0.0242 \\ \text { C6 } & -0.0004 & -0.0031 & -0.0038 & -0.0197 & -0.0375\end{array}$

Table 3: Bias

$\begin{array}{llll}\text { Instrument } & \text { Acetone } 0.5 \mathrm{mg} / \mathrm{L} & \text { Isopropanol } 0.1 \mathrm{mg} / \mathrm{L} & \text { Methanol } 0.1 \mathrm{mg} / \mathrm{L} \\ \text { Pro } & 0.000 & 0.010 & 0.043 \\ \text { C8 } & 0.000 & 0.008 & 0.027 \\ \text { C6 } & 0.000 & 0.009 & 0.032\end{array}$

Table 4: Aparent Ethanol Response to Interfering Substances 


\section{Discussion}

\section{Analytical Performance}

The analyzers exhibited good performance at measuring vaporous ethanol in vitro, especially considering the low cost of the devices. At the $0.080 \mathrm{~g} / 210 \mathrm{~L}$ concentration, for example, both the $\mathrm{C} 6$ and the $\mathrm{C} 8$ showed levels of uncertainty similar to those found in more advanced breath alcohol analyzers used for evidential purposes $(44 ; 45)$.

In the United States, the National Highway Traffic Safety Administration (NHTSA) promulgates performance recommendations for alcohol screening devices (ASDs) (46). The NHTSA's total allowable error for ASDs at the $0.020 \mathrm{~g} / 210 \mathrm{~L}$ ethanol vapor concentration is $\pm 0.012 \mathrm{~g} / 210 \mathrm{~L}$ at the $95 \%$ coverage interval. The analyzers examined met this requirement, showing a total error of $\leq \pm 0.003 \mathrm{~g} / 210 \mathrm{~L}$ at $0.020 \mathrm{~g} / 210 \mathrm{~L}$ concentration, although they are not listed on the NHTSA's ASDs conforming products list (47).

For in vivo use, manufacturers of these devices should consider programing the instrument for a duplicate breath test sequence, reporting the mean of the two measurements along with the associated uncertainty. An uncertainty function could be built into the software of the smartphone app to provide users with additional information about the uncertainty of the measurements obtained (48). Also, calibration reports could be recorded by the smartphone app and notify the user when recalibration is needed.

\section{Potential Interfering Substances}

Potential interfering substances are volatile organic substances other than ethanol on a person's breath which has the potential to interfere with the accurate analysis of vaporous ethanol $(49 ; 50 ; 51 ; 52 ; 53)$. These substances have an impairing effect similar to or greater than ethanol $(54 ; 37)$. Normally, potential interfering substances are found in such low concentrations that they are unlikely to interfere with an ethanol breath test (55). However, there are some circumstances in which interfering substances may be present in high enough concentrations that they may falsely elevate an ethanol breath test $(56 ; 57 ; 58)$. The

analyzers examined do not have an interfering substance detection mechanism such as those found in more advanced electrochemical analyzers (59). 


\section{Acetone}

Acetone has been found in the breath of people with diabetes, during times of fasting, and in very low carbohydrate dieters (60). Electrochemical fuel cell breath alcohol analyzers are known to be unaffected by acetone (61). The analyzers examined in this study use a fuel cell and did not respond to acetone.

\section{Isopropanol}

Isopropanol may be present in elevated concentrations on a person's breath after drinking denatured alcohol $(62 ; 63 ; 53)$ or produced endogenously from the biotransformation of acetone to isopropanol (64). In one case study, a self-reported teetotaler obtained a false positive result on an electrochemical fuel cell breath alcohol analyzer after following a very low carbohydrate ketogenic diet (57). In another study, isopropanol in the breath was found to be elevated after eating a ketogenic meal (65). The analyzers showed an apparent ethanol response to isopropanol. Users engaged in very low carbohydrate ketogenic dieting should be aware of the possibility of obtaining elevated BrAC results based on their diet.

\section{Methanol}

Methanol may be present in elevated concentrations on a person's breath after consuming large amounts of fruit (66), in alcoholics $(67 ; 68)$, or through accidental exposure due to the improper production of distilled spirits $(69 ; 70 ; 71)$. There are two unfortunate cases reported in the literature where a breath alcohol analyzer mistook methanol for ethanol, delaying medical treatment, resulting in the subjects dying from methanol poisoning (51). Users of these devices should be aware of the potential, but the unlikely possibility of elevated $\mathrm{BrAC}$ results due to methanol.

\section{Limitations}

Vaporous ethanol reference material produced by breath simulators cannot account for the complex physiologic gas exchange taking place in the lungs and airways of live subjects (72; $22 ; 73 ; 74 ; 75 ; 76)$. The SD of measurements taken in vivo has been shown to be greater than the SD produced by breath simulators (77). Further research is needed to determine the measurement uncertainty for in vivo results. 
The calibration longevity of the analyzers was not examined in this study. An important consideration for those wishing to use these instruments is that the device must be sent back to the manufacturer regularly for recalibration. Individuals or institutions using these instruments may need to keep several on hand while periodic recalibrations are performed. Users of these instruments should incorporate quality assurance practices to ensure the accuracy meets the requirements of the intended use (78). The use of compressed ethanol-gas reference standards would be a convenient way to perform accuracy checks $(79 ; 80)$. Further investigation with these analyzers using compressed ethanol-gas standards is needed, as the efficacy was not assessed in this study.

\section{Conclusions}

The breath alcohol analyzers examined in this study showed the ability to measure vaporous ethanol with confidence in the results, especially at concentrations $\leq 0.080 \mathrm{~g} / 210 \mathrm{~L}$. At the $0.080 \mathrm{~g} / 210 \mathrm{~L}$ ethanol vapor concentration, the combined expanded measurement uncertainty was $\leq \pm 0.013 \mathrm{~g} / 210 \mathrm{~L}$ at the $95 \%$ coverage interval for all instruments. The likelihood of false readings from potential interfering substances appears to be small but may be a concern for those engaged in ketogenic diets with elevated levels of isopropanol. More work needs to be conducted with these instruments in vivo to determine the measurement uncertainty for the results which include a biological component.

\section{Conflicts of Interest}

None.

\section{Declaration}

All statements and opinions are solely that of the author.

\section{Supplementary Data}

\section{Hosted file}


BACtrack Testing Process.mp4 available at https://authorea.com/users/308674/ articles/441398-in-vitro-evaluation-of-bactrack-s-smartphone-connectedpersonal-breath-alcohol-analyzers

\section{Hosted file}

Supplementary data BACtrack study.xlsx available at https://authorea.com/ users/308674/articles/441398-in-vitro-evaluation-of-bactrack-s-smartphoneconnected-personal-breath-alcohol-analyzers

\section{References}

1. Gordon A, Jaffe A, McLellan AT, Richardson G, Skipper G, Sucher M, et al. How Should Remote Clinical Monitoring Be Used to Treat Alcohol Use Disorders?. Journal of Addiction Medicine [Internet]. 2017;11(2):145-53. Available at: https://doi.org/10.1097\%2Fadm . 0000000000000288

2. Gimpe H, Nißen M, Görlitz RA. Quantifying the quantified self: A study on the motivation of patients to track their own health. In: International Conference on Information Systems (ICIS 2013): Reshaping Society Through Information Systems Design [Internet]. 2013. p. 3286-301. Available at: https : //www . semanticscholar .org/paper/Quantifying-the-Quantified-Self\%3A-AStudy-on-the-of-Gimpel-Ni\%C3\%9Fen/7ccbe2e99078317a8657a2d362cdeb755b323cf4

3. Lupton D. Self-tracking health and medicine. Health Sociology Review [Internet]. November 2016;26(1):1-5. Available at: https://doi .org/10.1080\%2F14461242.2016.1228149

4. Lang E, Stockwell T, Rydon P, Beel A. Can training bar staff in responsible serving practices reduce alcohol-related harm?. Drug and Alcohol Review [Internet]. March 1998;17(1):39-50. Available at: https://doi.org/10.1080\%2F09595239800187581

5. Gibb KA, Yee AS, Johnston CC, Martin SD, Nowak RM. Accuracy and usefulness of a breath alcohol analyzer. Annals of Emergency Medicine. July 1984;13(7):516-20.

6. Indig D, Copeland J, Conigrave KM, Rotenko I. Why are alcohol-related emergency department presentations under-detected? An exploratory study using nursing triage text. Drug and Alcohol Review. November 2008;27(6):584-90.

7. Horra P, Wallace D, MacKenzie B. The admissibility of alcohol test results from 
Soberlink device in family law cases. Justice Speakers Institute [Internet]. 2018;:1-15. Available at: http://justicespeakersinstitute.com/wp-content/uploads/2018/12/ Soberlink-Final.pdf

8. Riordan BC, Scarf D, Moradi S, Flett JAM, Carey KB, Conner TS. The accuracy and promise of personal breathalysers for research: Steps toward a cost-effective reliable measure of alcohol intoxication?. Digital Health. January 2017;3.

9. Miller TR, Zaloshnja E, Spicer RS. Effectiveness and benefit-cost of peer-based workplace substance abuse prevention coupled with random testing. Accident Analysis and Prevention. May 2007;39(3):565-73.

10. Van Tassel WE. An evaluation of pocket-model, numerical readout breath alcohol testing instruments [Internet] [PhD thesis]. Texas A\&M University; 2003. Available at: https://oaktrust.library.tamu.edu/bitstream/handle/1969.1/1159/etd-tamu2003B-2003070311-Van-1.pdf

11. Ashdown HF, Fleming S, Spencer EA, Thompson MJ, Stevens RJ. Diagnostic accuracy study of three alcohol breathalysers marketed for sale to the public. BMJ Open [Internet]. December 2014;4(12):e005811. Available at: https ://doi .org/10.1136\%2Fbmjopen-2014005811

12. Delgado MK, Huang Y, Wanner K, Goldberg E, Hemmons J, Spencer E, et al. 39 Test accuracy of smartphone-paired breathalysers: a validation study. In: Oral presentations [Internet]. BMJ Publishing Group Ltd; 2017. Available at: https://doi.org/10.1136\% 2Finjuryprev-2017-042560.39

13. Riordan BC, Scarf D, Moradi S, Flett JAM, Carey KB, Conner TS. The accuracy and promise of personal breathalysers for research: Steps toward a cost-effective reliable measure of alcohol intoxication?. DIGITAL HEALTH [Internet]. January 2017;3:205520761774675. Available at: https://doi.org/10.1177\%2F2055207617746752

14. Rosenberg E. A Study of the Accuracy and Precision of Selected Breath Alcohol Measurement Devices ('Breathalyzers') [Internet]. Vienna University of Technology; 2015. Available at: https://www.ace-technik.com/documents/products/Media/Alcotest_Study.pdf

15. Delgado MK, Shofer F, Wetherill R, Curtis B, Hemmons J, Spencer E, et al. Accuracy of Consumer-marketed smartphone-paired alcohol breath testing devices: A laboratory validation study. Alcoholism: Clinical and Experimental Research [Internet]. May 
2021;45(5):1091-9. Available at: https://doi.org/10.1111\%2Facer. 14597

16. BACtrack Mobile Pro [Internet]. Available at: https://www.bactrack.com/products/ bactrack-mobile-smartphone-breathalyzer

17. BACtrack C8 [Internet]. Available at: https://www.bactrack.com/products/ bactrack-c8-breathalyzer

18. BACtrack C6 Keychain [Internet]. Available at: https://www.bactrack.com/ products/bactrack-c6-smartphone-keychain-breathalyzer

19. Anstie FE. Prognosis and treatment of certain acute diseases. In: The Lancet. 1867. p. $385-7$.

20. Bogen E. Drunkenness: A quantitative study of acute alcoholic intoxication. Journal of the American Medical Association. October 1927;89(18):1508-11.

21. Caddy GR, Sobell MB, Sobell LC. Alcohol breath tests: criterion times for avoiding contamination by mouth alcohol. Behavior Research Methods \& Instrumentation. November 1978;10(6):814-8.

22. Gullberg RG. The mathematical analysis of breath alcohol profiles generated during breath exhalation. Journal of Analytical Toxicology. 1990;14(6):358-67.

23. Spector NH. Alcohol breath tests: gross errors in current methods of measuring alveolar gas concentrations. Science. 1971;172(3978):57-9.

24. Pon RA, Dagenais C, Macalpine RA. Are mouth alcohol defenses valid or invalid? The BAC Datamaster $C^{T M}$ INVALID SAMPLE status message. Journal of the Canadian Society of Forensic Science. 2002;35(3):153-8.

25. BACtrack. Bactrack mobile breathalyzer for iPhone and Android devices [Internet]. 2019 [cited July 29, 2019]. Available at: https ://www . bactrack.com/products/bactrackmobile-smartphone-breathalyzer

26. Wigmore JG, Langille RM. Six generations of breath alcohol testing instruments: Changes in the detection of breath alcohol since 1930. An historical overview. Vol. 42, Journal of the Canadian Society of Forensic Science. 2009. p. 276-83.

27. Jones AW. Alcohol, its analysis in blood and breath for forensic purposes, impairment effects, and acute toxicity. Wiley Interdisciplinary Reviews: Forensic Science. July 
2019;1(6):1-32.

28. Jones AW. Alcohol, its absorption, distribution, metabolism, and excretion in the body and pharmacokinetic calculations. Wiley Interdisciplinary Reviews: Forensic Science. September 2019;1(5).

29. BACtrack. Bactrack View ${ }^{\top M}$ - remote alcohol monitoring for iOS devices [Internet]. BACtrack View. 2019 [cited July 30, 2019]. Available at: https://monitoring.bactrack . com/

30. Dubowski KM. Breath-Alcohol Simulators: Scientific Basis and Actual Performance. Journal of Analytical Toxicology [Internet]. September 1979;3(5):177-82. Available at: http://academic.oup.com/jat/article/3/5/177/686322/BreathAlcoholSimulators-Scientific-Basis-and

31. Kucharski D, Lemanik A. Calibration system for breath-alcohol analysers. Journal of Physics: Conference Series [Internet]. August 2018;1065:242004. Available at: https: //doi.org/10.1088\%2F1742-6596\%2F1065\%2F24\%2F 242004

32. Anghel M MA; Buzoianu. Traceability of the mass concentration of exhaled breath alcohol measurements and associated uncertainty evaluation in Romania. OIML Bulletin [Internet]. 2009;L. Available at: https://www.oiml.org/en/publications/bulletin/pdf/ oiml_bulletin_jan_2009.pdf

33. Canadian Society of Forensic Science Alcohol Test Committee Equipment Standards and Evaluation Procedures [Internet]. Available at: https://www.csfs.ca/wp-content/ uploads/2018/12/2018-12-18-Equipment-Evaluation-Procedures .pdf

34. OIML R 126: International Recommend for Evidential breath analyzers [Internet]. International Organization of Legal Metrology; 1998. Available at: https://www.oiml. org/en/files/pdf_r/r126-e98.pdf

35. Henry W. Experiments on the quantity of gases absorbed by water, at different temperatures, and under different pressures. Proceedings of the Royal Society of London. December $1832 ; 1(0): 103-4$.

36. Harger R.N., Raney B.B., Bridwell E.G., Kitchel M.F.. The Partition Ratio of Alcohol Between Air and Water, Urine and Blood; Estimation and Identification of Alcohol in These Liquids From Analysis of Air Equilibrated With Them. Journal of Biological Chemistry [Internet]. 1950;183(1):197-213. Available at: https://www. jbc.org/content/183/1/197. 
citation

37. Cowan JM, McCutcheon JR, Weathermon A. The response of the Intoxilyzer 4011AS-A to a number of possible interfering substances. J Forensic Sci [Internet]. 1990;35(4):797-812. Available at: https://www.ncbi.nlm.nih.gov/pubmed/2391473

38. Scientific Working Group for Forensic Toxicology (SWGTOX) Standard Practices for Method Validation in Forensic Toxicology. Journal of Analytical Toxicology [Internet]. August 2013;37(7):452-74. Available at: https ://doi.org/10.1093\%2Fjat\%2Fbkt054

39. Ishikawa K. Introduction to Quality Control [Internet]. Dordrecht: Springer Netherlands; 1989. Available at: https://www.springer.com/gp/book/9789401176903

40. Joint Committee for Guides in Metrology. Evaluation of measurement data - guide to the expression of uncertainty in measurement [Internet]. 2008 Sep p. 1-134. Report No.: 100:2008. Available at: https://www.bipm.org/utils/common/documents/jcgm/ JCGM_100_2008_E.pdf

41. Taylor BN, Kuyatt CE. Guidelines for evaluating and expressing the uncertainty of NIST measurement results [Internet]. Gaithersburg, MD: US Department of Commerce, Technology Administration, National Institute of ...; 1994. Report No.: 1297. Available at: https://nvlpubs.nist.gov/nistpubs/Legacy/TN/nbstechnicalnote1297.pdf

42. Magnusson B, Ellison SLR. Treatment of uncorrected measurement bias in uncertainty estimation for chemical measurements. Analytical and Bioanalytical Chemistry [Internet]. January 2008;390(1):201-13. Available at: http://link.springer.com/10.1007/s00216007-1693-1

43. Phillips SD, Eberhardt KR, Parry B. Guidelines for expressing the uncertainty of measurement results containing uncorrected bias. Journal of Research of the National Institute of Standards and Technology. 1997;102(5):577-85.

44. Hwang R-J, Rogers C, Beltran J, Razatos G, Avery J. Measurement of Uncertainty for Vaporous Ethanol Concentration Analyzed by Intoxilyzer@8000 Instruments. Journal of Analytical Toxicology [Internet]. April 2016;40(5):338-44. Available at: https://doi.org/ 10. $1093 \% 2 \mathrm{Fjat} \% 2 \mathrm{Fbkw030}$

45. Brockley-Drinkman D, Barkholtz HM. Estimating Uncertainty in Wisconsin's Evidential Breath Alcohol Measurements. Journal of Analytical Toxicology [Internet]. July 2019;44(2):188-91. Available at: https://doi.org/10.1093\%2Fjat\%2Fbkz050 
46. National Highway Traffic Safety Administration. Model specifications for screening; devices to measure alcohol in bodily fluids. Federal Register [Internet]. 2008;73(62):16956-60. Available at: https://www.federalregister.gov/documents/2008/03/31/E86520/highway-safety-programs-model-specifications-for-screening-devicesto-measure-alcohol-in-bodily

47. National Highway Traffic Safety Administration. Highway Safety Programs; Conforming Products List of Screening Devices To Measure Alcohol in Bodily Fluids [Internet]. 2012. Available at: https://www.federalregister.gov/documents/2012/06/14/201214582/highway-safety-programs-conforming-products-list-of-screeningdevices-to-measure-alcohol-in-bodily

48. Gullberg RG, Polissar NL. Factors contributing to the variability observed in duplicate forensic breath alcohol measurement. Journal of Breath Research [Internet]. February 2011;5(1):016004. Available at: https://doi.org/10.1088\%2F $1752-7155 \% 2 \mathrm{~F} 5 \% 2 \mathrm{~F} 1 \%$ $2 \mathrm{~F} 016004$

49. Gullberg RG. The frequency of apparent acetone in a group of breath alcohol data: statistical treatment and forensic implications. Forensic Science International. June 1994;67(1):65-72.

50. Jones AW, Andersson L, Berglund K. Interfering substances identified in the breath of drinking drivers with Intoxilyzer 5000S. Journal of Analytical Toxicology. 1996;20(7):522-7.

51. Jones AW. Observations on the specificity of breath-alcohol analyzers used for clinical and medicolegal purposes.. Journal of forensic sciences. July 1989;34(4):842-7.

52. Jones AW, Andersson L. Determination of ethanol in breath for legal purposes using a five-filter infrared analyzer: Studies on response to volatile interfering substances. Journal of Breath Research [Internet]. June 2008;2(2):026006. Available at: http://stacks.iop. org $/ 1752-7163 / 2 / i=2 / a=026006$ ?key=crossref $.4 a 0 c 128 c 7531$ de85439f c64f09806ae3

53. Logan BK, Gullberg RG, Elenbaas JK. Isopropanol Interference with Breath Alcohol Analysis: A Case Report. Journal of Forensic Sciences [Internet]. July 1994;39(4):13691J. Available at: https://doi.org/10.1520\%2Fjfs13691j

54. Caldwell JP, Kim ND. The response of the Intoxilyzer 5000 to five potential interfering substances. J Forensic Sci [Internet]. November 1997;42(6):1080-7. Available at: https: //www.ncbi.nlm.nih.gov/pubmed/9397550 
55. Flores AL, Frank JF. The likelihood of acetone interference in breath alcohol measurement [Internet]. Washington, DC: National Highway Traffic Safety Administration; 1985 p. 23. Available at: https://rosap.ntl.bts.gov/view/dot/1406

56. Caravati EM, Anderson KT. Breath Alcohol Analyzer Mistakes Methanol Poisoning for Alcohol Intoxication. Annals of Emergency Medicine. 2010;55(2):198-200.

57. Jones AW, Rössner S. False-positive breath-alcohol test after a ketogenic diet. International Journal of Obesity. March 2007;31(3):559-61.

58. Norfolk GA, Quartly CF. Volatile substances and their potential to interfere with breath alcohol reading instruments. Journal of Clinical Forensic Medicine [Internet]. March 1997;4(1):21-3. Available at: https://linkinghub.elsevier.com/retrieve/pii/ S1353113197900043

59. Chan K. The response of the Intox EC/IR II to isopropanol and isopropanol/ethanol mixtures. Canadian Society of Forensic Science Journal [Internet]. October 2018;51(34):67-82. Available at: https://doi.org/10.1080\%2F00085030.2018.1491691

60. Ruzsányi V, Kalapos MP. Breath acetone as a potential marker in clinical practice. Journal of Breath Research. June 2017;11(2).

61. Falkensson M, Jones W, Sörbo B. Bedside diagnosis of alcohol intoxication with a pocket-size breath-alcohol device: sampling from unconscious subjects and specificity for ethanol.. Clinical Chemistry [Internet]. June 1989;35(6):918-21. Available at: https: //academic.oup.com/clinchem/article/35/6/918-921/5663083

62. Jones AW, Lund M, Andersson E. Drinking drivers in sweden who consume denatured alcohol preparations: An analytical-toxicological study. Journal of Analytical Toxicology. 1989;13(4):199-203.

63. Jones AW. Driving Under the Influence of Isopropanol. Journal of Toxicology: Clinical Toxicology [Internet]. January 1992;30(1):153-5. Available at: https://doi .org/10.3109\% 2F15563659208994457

64. Jones AW, Andersson L. Biotransformation of acetone to isopropanol observed in a motorist involved in a sobriety check.. J Forensic Sci. 1995;40:686-7.

65. Li W, Liu Y, Liu Y, Cheng S, Duan Y. Exhaled isopropanol: new potential biomarker in diabetic breathomics and its metabolic correlations with acetone. RSC Advances. 
$2017 ; 7(28): 17480-8$.

66. Lindinger W, Taucher J, Jordan A, Hansel A, Vogel W. Endogenous production of methanol after the consumption of fruit. Alcoholism: Clinical and Experimental Research. 1997;21(5):939-43.

67. Wigmore JG. The effect of an elevated serum methanol concentration on the intoxilyzer 5000 c results of a drinking driver. Journal of the Canadian Society of Forensic Science. 2008;41(3):171-4.

68. Jones AW, Löwinger H. Relationship between the concentration of ethanol and methanol in blood samples from Swedish drinking drivers. Forensic Science International. June 1988;37(4):277-85.

69. Kane RL, Talbert W, Harlan J. A Methanol Poisoning Outbreak in Kentucky. Archives of Environmental Health. 1968;17(1):119-29.

70. Paasma R, Hovda KE, Tikkerberi A, Jacobsen D. Methanol mass poisoning in Estonia: outbreak in 154 patients. Clinical Toxicology. 2007;45(2):152-7.

71. Aghababaeian H, Ahvazi LA, Ostadtaghizadeh A. The Methanol Poisoning Outbreaks in Iran 2018. Alcohol and Alcoholism [Internet]. January 2019;54(2):128-30. Available at: https ://doi .org/10.1093\%2Falcalc\%2Fagz005

72. Jones AWW. Physiological aspects of breath measurement. Alcohol, Drugs and Driving [Internet]. 1990;6(2):1-25. Available at: https://duiform.weebly.com/uploads/ 1/2/0/1/12016444/physiological_aspects_of_breath_alcohol_measurement_1990jones.pdf

73. Anderson JC, Babb AL, Hlastala MP. Modeling soluble gas exchange in the airways and alveoli. Annals of Biomedical Engineering. December 2003;31(11):1402-22.

74. Lubkin SR, Gullberg RG, Logan BK, Maini PK, Murray JD. Simple versus sophisticated models of breath alcohol exhalation profiles. Alcohol and Alcoholism. 1996;31(1):61-7.

75. Wilson HK. Breath analysis. Physiological basis and sampling techniques. Scandinavian Journal of Work, Environment and Health. 1986;12(3):174-92.

76. Vosk T, Forrest ARW, Emery A, Mclane LD. The measurand problem in breath alcohol testing. Journal of Forensic Sciences. 2014;59(3):811-5. 
77. Gullberg RG. Breath alcohol test precision: An in vivo vs. in vitro evaluation. Forensic Science International. 1989;43(3):247-55.

78. Dubowski KM. Quality assurance in breath-alcohol analysis. J Anal Toxicol. 1994;18:306-11.

79. Dubowski KM, Essary NA. Vapor-alcohol control tests with compressed ethanol-gas mixtures: scientific basis and actual performance. J Anal Toxicol [Internet]. October 1996;20(6):484-91. Available at: http://dx.doi.org/10.1093/jat/20.6.484

80. Silverman LD, Wong K, Miller S. Confirmation of ethanol compressed gas standard concentrations by an NIST-traceable, absolute chemical method and comparison with wet breath alcohol simulators. J Anal Toxicol [Internet]. September 1997;21(5):369-72. Available at: http://dx.doi.org/10.1093/jat/21.5.369 